\title{
Secondary electron yield of Cu technical surfaces: Dependence on electron irradiation
}

\author{
R. Larciprete, ${ }^{1,2}$ D. R. Grosso, ${ }^{2}$ M. Commisso, ${ }^{2}$ R. Flammini, ${ }^{3,2}$ and R. Cimino ${ }^{2}$ \\ ${ }^{1}$ CNR-ISC Istituto dei Sistemi Complessi, Via Fosso del Cavaliere 100, 00133 Roma, Italy \\ ${ }^{2}$ LNF-INFN, Via E. Fermi 40, 00044 Frascati, Rome, Italy \\ ${ }^{3}$ CNR-IMIP Istituto Metodologie Inorganiche e Plasmi, Via Salaria Km. 29.300, 00019 Monterotondo Scalo, Rome, Italy
}

(Received 15 October 2012; published 9 January 2013)

\begin{abstract}
The secondary emission yield (SEY) properties of colaminated $\mathrm{Cu}$ samples for LHC beam screens are correlated to the surface chemical composition determined by x-ray photoelectron spectroscopy. The surface of the as-received samples is characterized by the presence of significant quantities of contaminating adsorbates and by the maximum of the SEY curve $\left(\delta_{\max }\right)$ being as high as 2.1. After extended electron scrubbing at kinetic energy of 10 and $500 \mathrm{eV}$, the $\delta_{\max }$ value drops to the ultimate values of 1.35 and 1.1, respectively. In both cases the surface oxidized phases are significantly reduced, whereas only in the sample scrubbed at $500 \mathrm{eV}$ the formation of a graphitic-like $\mathrm{C}$ layer is observed. We find that the electron scrubbing of technical $\mathrm{Cu}$ surfaces can be described as occurring in two steps: the first step consists in the electron-induced desorption of weakly bound contaminants that occurs indifferently at 10 and at $500 \mathrm{eV}$ and corresponds to a partial decrease of $\delta_{\max }$; the second step, activated by more energetic electrons and becoming evident at high doses, increases the number of graphitic-like $\mathrm{C}-\mathrm{C}$ bonds via the dissociation of adsorbates already contaminating the as-received surface or accumulating on this surface during irradiation. Our results demonstrate how the kinetic energy of impinging electrons is a crucial parameter when conditioning the surfaces of $\mathrm{Cu}$ and other metals by means of electron-induced chemical processing.
\end{abstract}

DOI: 10.1103/PhysRevSTAB.16.011002

PACS numbers: 29.27.- a, 68.43.-h, 79.20.Hx

\section{INTRODUCTION}

A wide range of applications [1-3] use or are dependent on the capability of a given material to emit electrons after electron bombardment. This quantity, called secondary electron yield (SEY), is defined as the ratio of the number of emitted (or secondary) electrons to the number of incident primary electrons [4], and is commonly denoted by $\delta$. The SEY $(\delta)$ curves, which are characterized by the behavior at low energy [5] and by the asymptotic value at high energy of the incident electrons, for many purposes can be schematically described by their maximum value $\left(\delta_{\max }\right)$ and the energy at which it occurs $\left(E_{\max }\right)$. Our experiments are performed in the context of particle accelerator research, since intense and positively charged beams circulating in vacuum chambers of small transverse dimensions may interact with low energy electrons also present in the vacuum chamber and lose the desired properties. The low energy electrons, produced either by synchrotron radiation hitting the accelerator walls $[6,7]$ or by direct ionization of residual gases, might undergo a rapid multiplication driven by the actual SEY properties of the wall surface. In fact, the seeding primary electrons "see" the circulating beam, are accelerated in a complex dynamics

Published by the American Physical Society under the terms of the Creative Commons Attribution 3.0 License. Further distribution of this work must maintain attribution to the author(s) and the published article's title, journal citation, and DOI. (studied in details in different simulation codes developed to this purpose) [8-12], and hit the vacuum wall. The secondary electrons are produced and a multiplication, resonant with the beam time structure, may occur if the accelerator wall surface possesses a SEY larger than unity. This can cause a sudden increase of the number of electrons in the accelerator, inducing detrimental effects on beam quality as well as rapid vacuum pressure rises resulting in beam loss. This phenomenon is called electron cloud buildup, and has been recognized as a problem in positron/ proton rings like DAFNE, B (Beauty) factories, PEP-II, KEKB [13-17], and LHC among others.

A mean to mitigate this problem is to exploit the conditioning or scrubbing effect that the prolonged electron irradiation has on the chemical state of the wall surface and that often coincides with a significant reduction of the SEY $[13,16]$. LHC, for instance, bases its ability to run at operation conditions on a drastic reduction of the initially high SEY $\left(\delta_{\max } \sim 2.1\right)$ of the $\mathrm{Cu}$ surface seeing the beam in the cryogenic dipoles, to a much lower value $\left(\delta_{\max } \sim 1.1\right)$ after a certain electron dose. Electron scrubbing is considered then necessary to reach nominal operation [13-15,18].

The scope of this study is the detailed comprehension of the chemistry variations induced by electron irradiation on technical surfaces, i.e., samples representative of the accelerator walls, exposed to air and not treated with specific cleaning procedures in vacuum. Recent studies have demonstrated that the beneficial effect of electron beam scrubbing on these surfaces in some cases coincides with 
the formation of a graphitic surface film $[19,20]$. Since the SEY of graphite and, in general, of carbon based materials is lower than that of air exposed metals, the presence of the C thin films reduces the effective SEY of the surface [21]. Graphitic film growth occurs because, in general, the technical surfaces are covered by $\mathrm{C}$ containing contaminants that once exposed to the electron flux tend to decompose and partly rearrange in graphitic assemblies [22,23]. The occurrence of material transformation at the atomic level induced by electron irradiation has been often reported in the case of thin films and nanostructures [24,25]. In particular, the graphitization of carbonaceous films is a frequent process and relies on the higher stability of graphitic lattice at or below ambient pressure over the other possible $\mathrm{C}$ allotropic structures. The electron-induced chemical reactions at the basis of contaminant graphitization lead to the dissociation of $\mathrm{C}-\mathrm{H}[26,27]$ and $\mathrm{C}-\mathrm{O}$ bonds and to the formation of volatile compounds that desorb from the surface. In parallel $\mathrm{C}-\mathrm{C}$ bonds reorganize from the openchain geometry, typical of aliphatic hydrocarbons, to form domains with the honeycomb arrangement characteristic of the graphitic materials, due to the transition of the $\mathrm{C}$ atoms from the $\mathrm{sp}^{3}$ to the $\mathrm{sp}^{2}$ hybridization state. Moreover, since the incident electrons are emitted by a hot filament, this, if not properly degassed, could contribute to a local increase of C-containing contaminants. In addition to that, the electron beam might also induce the deposition of a thin graphitic layer by dissociating C-containing gas phase molecules present in the residual pressure of the vacuum chamber [28]. This process, which is certainly more relevant in low vacuum environments, might occur even in ultrahigh vacuum regimes $\left(10^{-9}-10^{-10}\right.$ mbar) due to the dissociation of molecules such as $\mathrm{CO}$ and $\mathrm{CO}_{2}$ that are usual components of the residual gas. In fact, the growth of thin carbon layers is routinely observed on surfaces exposed to high-energy

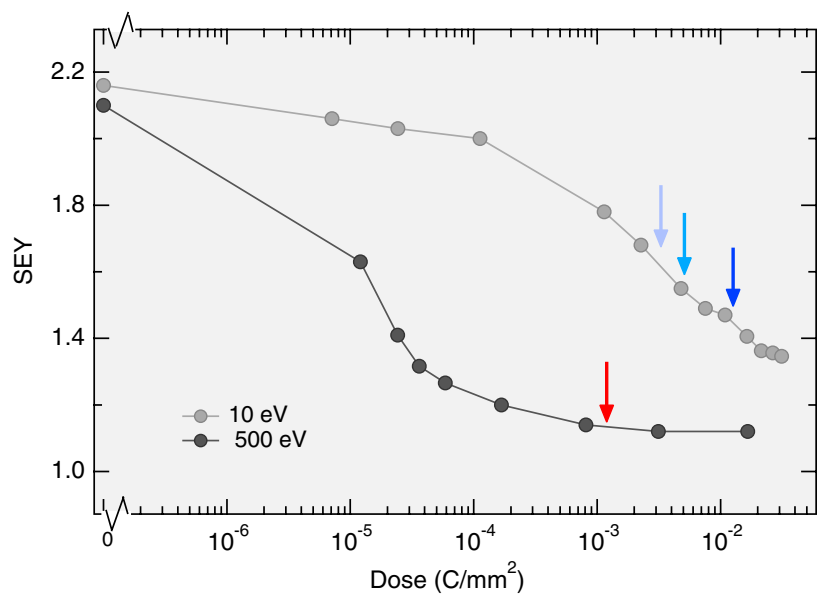

FIG. 1. $\delta_{\max }$ values measured on colaminated $\mathrm{Cu}$ samples for LHC beam screen as a function of the electron dose at $E_{p}=$ $500 \mathrm{eV}$ (dark grey) and $10 \mathrm{eV}$ (light grey) [20]. The arrows indicate the doses used in this experiment. radiation as in electron microscopy [29], extreme ultraviolet lithography $[3,30]$, or synchrotron radiation beam lines [31]. Both the graphitization of the preexisting contaminating layer and the growth of a graphitic film due to the cracking of the residual gas molecules occur with a different efficiency depending on the kinetic energy of the electrons used to scrub the surface.

Recently, the effect of the kinetic energy of the scrubbing electrons on the SEY has been investigated in the case of colaminated $\mathrm{Cu}$ for LHC beam screens which, when characterized "as-received" shows a $\delta_{\max }$ of $\sim 2.2$ [20]. At each kinetic energy of the primary beam $\left(E_{p}\right)$ between 10 and $500 \mathrm{eV}$, electron scrubbing was found to lower the SEY, with $\delta_{\max }$ decreasing asymptotically down to an ultimate minimum value, which, for kinetic energy between 50 and $500 \mathrm{eV}$ is 1.1 , whereas for kinetic energy of $10 \mathrm{eV}$ remains around 1.35 [20]. The stability of the $\delta_{\max }$ values after further irradiation indicates that the samples are in each case "fully scrubbed" at the corresponding energy. This is shown in Fig. 1 for the $\delta_{\max }$ curves taken at $E_{p}=10$ and $500 \mathrm{eV}$. As a consequence, the majority of the electrons forming the e-cloud in the LHC, which have energy below $20 \mathrm{eV}$ [20], do not contribute in lowering $\delta_{\max }$ below the value of 1.3 desired for machine stability at design operation $[13-15,18]$. The relevance of this issue for accelerator wall conditioning motivates deep investigations of the effects of the electron kinetic energy on the surface chemistry of technical metal surfaces.

In this study the SEY properties of colaminated $\mathrm{Cu}$ samples for LHC beam screens scrubbed at 10 and $500 \mathrm{eV}$ were correlated to the surface chemical composition determined by $\mathrm{x}$-ray photoelectron spectroscopy (XPS). Our results show that electron scrubbing at $10 \mathrm{eV}$ efficiently removes many contaminating species from the sample surface diminishing significantly the oxygen content, but fails to induce a substantial graphitization. In contrast, the formation of a graphitic-like $\mathrm{C}$ layer is clearly observed on the surface scrubbed at $E_{p}=500 \mathrm{eV}$, whose SEY is satisfactorily mitigated.

\section{EXPERIMENTAL}

XPS and SEY measurements were performed at the Material Science Laboratory of the INFN-LNF in Frascati (RM). The experimental apparatus is described in detail elsewhere [6]. Briefly the UHV system (base pressure $2 \times 10^{-10}$ mbar) includes a $\mu$-metal chamber dedicated to SEY measurements and XPS analysis and a preparation chamber. The SEY $(\delta)$, i.e., the ratio of the number of electrons leaving the sample surface $\left(I_{s}\right)$ to the number of incident electrons $\left(I_{p}\right)$ per unit area, was determined experimentally by measuring $I_{p}$ and the total sample current $I_{T}=I_{p}-I_{s}$, so that $\delta=1-I_{T} / I_{p}$. For the SEY measurements, the electron beam was set to be smaller than $0.25 \mathrm{~mm}^{2}$ in transverse cross-sectional area 
at the sample surface. To measure the current of the impinging primary electrons, a negative bias voltage $(-75 \mathrm{~V})$ was applied to the sample. The SEY measurements and electron irradiation were performed at normal incidence, by using electron beam currents of a few nA (to induce minimal "scrubbing" during data acquisition) and $\sim 1-5 \mu \mathrm{A}$, respectively. In order to take XPS spectra in the electron irradiated regions the electron beam was scanned to scrub a $3 \times 3 \mathrm{~mm}^{2}$ area: therefore the doses delivered to the sample in this experiment were lower than those reached when irradiating a fixed point [20]. The SEY was found to fluctuate by 5\% at most. XPS spectra were acquired by exciting the sample with nonmonochromatic $\operatorname{MgK} \alpha$ photons $(h \nu=1253.6 \mathrm{eV})$ and by detecting the photoelectrons in normal emission geometry by means of a hemispherical electron analyzer. The analysis area of the electron analyzer was smaller than $1.5 \mathrm{~mm}^{2}$. The binding energies (BE) are referred to the Fermi level measured on the sample.

\section{RESULTS AND DISCUSSION}

Figure 2(a) shows the SEY curve measured on the asreceived sample (trace A) that exhibits a $\delta_{\max }$ value of 2.1. The XPS spectrum taken on this surface [see Fig. 2(c)] shows the $\mathrm{Cu}$ spectral features but also reveals the presence of $\mathrm{C}$ and $\mathrm{O}$ indicated by the $\mathrm{C} 1 \mathrm{~s}$ and $\mathrm{O} 1 \mathrm{~s}$ peaks at around 285 and $531 \mathrm{eV}$, respectively, due to surface contaminants after the prolonged permanence in air. The details of the $\mathrm{Cu} 2 \mathrm{p}_{3 / 2}, \mathrm{C} 1 \mathrm{~s}$, and $\mathrm{O} 1 \mathrm{~s}$ core level spectra are shown in Figs. 2(d)-2(f). The $\mathrm{Cu} 2 \mathrm{p}_{3 / 2}$ spectrum exhibits in addition to the metallic component at $932.6 \mathrm{eV}$ a shoulder at $934.2 \mathrm{eV}$ and a satellite structure at $\mathrm{BE} \sim 9 \mathrm{eV}$ higher due to the $\mathrm{CuO}$ oxide phase [32]. The $\mathrm{C} 1 \mathrm{~s}$ spectrum consists of a main structure peaked at $284.6 \mathrm{eV}$ and a weaker peak centered around $288.2 \mathrm{eV}$. The first peak can be related to the presence of $\mathrm{C}-\mathrm{C}$ and $\mathrm{C}-\mathrm{H}$ bonds, with the $\mathrm{C}$ atoms having on the average a hybridization state intermediate between $\mathrm{sp}^{2}$ and $\mathrm{sp}^{3}$, that are characterized by typical BE values of $\sim 284.3$ and $\sim 285.1 \mathrm{eV}[33,34]$, respectively, as indicated by the arrows in Fig. 2(e). This chemical arrangement derives from the different compounds forming the adsorbed layer. The high BE tail of the main C1s peak as well as the weaker peak at $288.2 \mathrm{eV}$ are indicative for the presence of $\mathrm{C}-\mathrm{OH}, \mathrm{C}-\mathrm{O}-\mathrm{C}$, and $\mathrm{C}=\mathrm{O}$ bonds [35]. The broad and asymmetric O1s spectrum peaked at $531.4 \mathrm{~V}$ comprises the contributions due to $\mathrm{O}$ atoms bonded to $\mathrm{Cu}$ and $\mathrm{C}$ atoms.

This sample was irradiated at a primary electron energy $E_{p}=500 \mathrm{eV}$ over an area of $3 \times 3 \mathrm{~mm}^{2}$ obtained by scanning the electron beam up to a total dose of $Q=1.2 \times$ $10^{-3} \mathrm{C} / \mathrm{mm}^{2}$. According to Fig. 1 this dose corresponds to a surface almost fully scrubbed. The effect of electron scrubbing was studied by comparing the chemical composition and the secondary electron emission measured inside and outside the irradiated area. After electron conditioning, the SEY curve measured in the center of the irradiated area shows a $\delta_{\max }$ value of 1.2 [see trace C in Fig. 2(a)]. This value is almost constant over a length of $2.3 \mathrm{~mm}$ along a line crossing the electron beam spot [red area in Fig. 2(b)], indicating a homogeneous scrubbing effect over the region. Higher values are measured in the periphery of the scrubbed region [violet area in Fig. 2(b)], in correspondence of the tails of the electron beam, where the delivered electron dose is lower. The SEY curve measured in the periphery of the scrubbed region [trace B in Fig. 2(a)] shows a $\delta_{\max }$ of 1.8. However, this value is strongly dependent on the exact position of the sampled point, as the highly sloping $\delta_{\max }$ curve shown in Fig. 2(b) indicates. On the other hand, far away from the irradiated region [grey circles in Fig. 2(b)], the sample maintains the $\delta_{\max }$ values typical of the as-received surface. The variation of the secondary emission corresponds to significant modifications of the surface chemical composition. The XPS spectra measured in the center and in the periphery of the irradiated area are compared in Figs. 2(g)-2(i). In the periphery region (violet curves), that is, in the area scrubbed at a lower electron dose, the oxide phase in the $\mathrm{Cu} 2 \mathrm{p}_{3 / 2}$ spectrum has disappeared and, consequently, the metallic component has gained intensity with respect to the as-received surface. The C1s spectrum as well has lost the $\mathrm{C}-\mathrm{O}$ component. Consistently, the intensity of the $\mathrm{O} 1 \mathrm{~s}$ spectrum has substantially decreased. These chemical modifications are likely due to the dissociation of $\mathrm{Cu}-\mathrm{O}$, $\mathrm{C}-\mathrm{H}[26,27]$, and $\mathrm{C}-\mathrm{O}$ bonds and to the recombination of volatile molecules as $\mathrm{O}_{2}$ and $\mathrm{H}_{2} \mathrm{O}$ that easily desorb under the action of the impinging electrons. In this reaction, a possible role of secondary electrons coming from the bulk of the sample cannot be excluded [36]. The loss of O-containing molecules reduces the oxidized components in the contaminated surface and results in a SEY decrease.

In the center of the scrubbed area the amount of $\mathrm{O}$ is even lower and the $\mathrm{C}$ peak has shifted to lower BE [20]. This means that, in addition to the reactions occurring at the periphery of the beam spot, here the impinging electrons have also converted for some $\mathrm{C}$ atoms the hybridization from $\mathrm{sp}^{3}$ into $\mathrm{sp}^{2}$. Such an effect usually is accompanied by a decrease of the SEY of technical surfaces $[19,20]$. Moreover, in the scrubbed area the C1s intensity which is $20 \%$ higher than in the periphery, hints at the occurrence of electron beam-induced deposition of graphitic-like $\mathrm{C}$. This is proven by the intensity of the substrate $\mathrm{Cu} 2 \mathrm{p}_{3 / 2}$ spectrum that, in the scrubbed region, is damped by the thicker surface coating with respect to the surrounding region [Fig. 2(g)]. The additional C layer growth originates from the dissociation of residual gas molecules present in the UHV chamber or even released by the hot $\mathrm{e}^{-}$beam filament, typically $\mathrm{CO}$ and $\mathrm{CO}_{2}$, which adsorb on the sample surface and are cracked by the impinging $500 \mathrm{eV}$ electrons. After the dissociation it is 

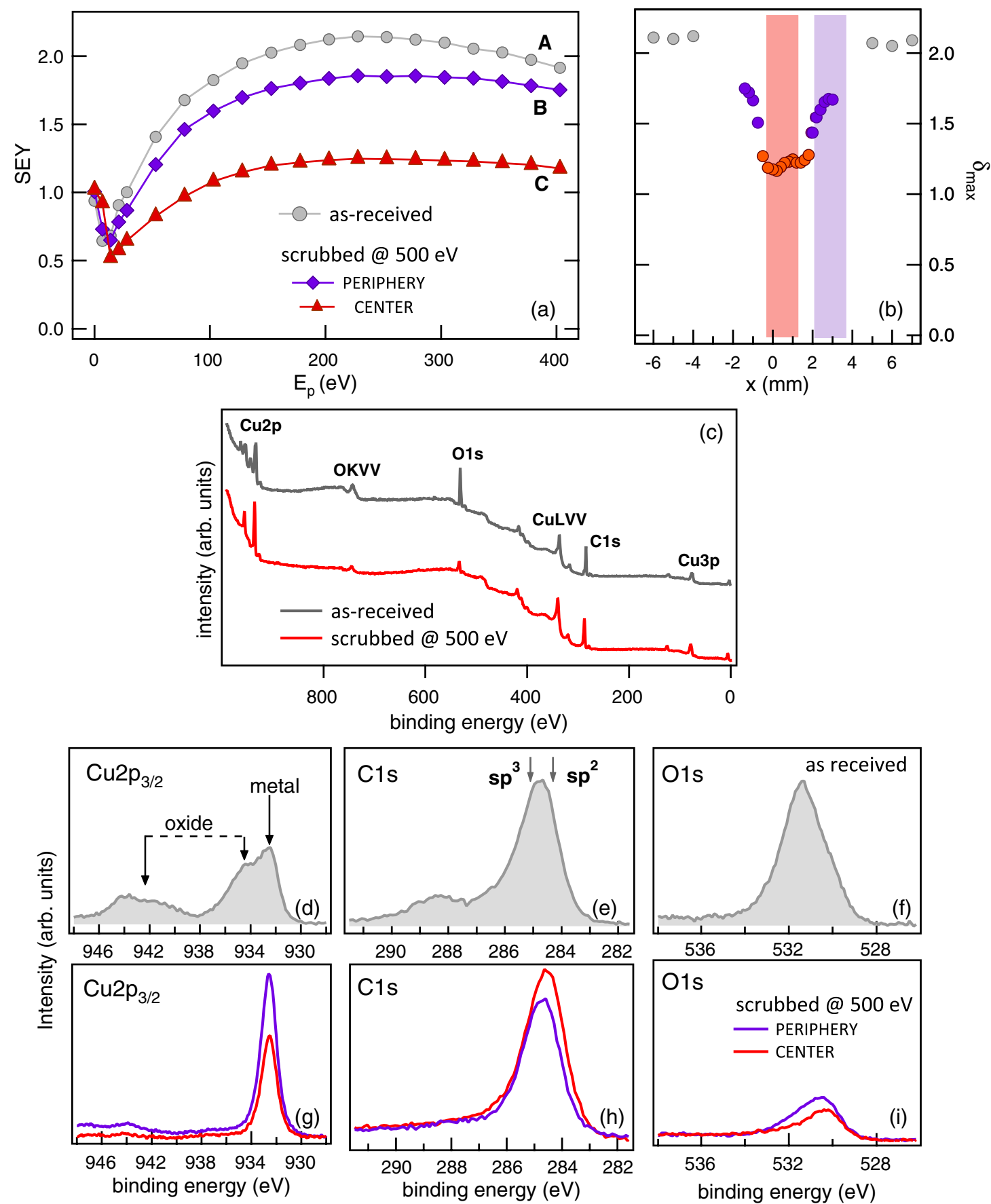

FIG. 2. (a) SEY curves measured on the as-received colaminated $\mathrm{Cu}$ sample for LHC beam screen (grey, circles) and in the middle (red, triangles) and in the periphery (violet, diamonds) of the sample area $\left(3 \times 3 \mathrm{~mm}^{2}\right)$ scrubbed with $500 \mathrm{eV}$ electrons $(1.2 \times$ $10^{-3} \mathrm{C} / \mathrm{mm}^{2}$ ); (b) $\delta_{\max }$ values measured along a line crossing the scrubbed region; (c) XPS spectra measured on the as-received sample (upper curve) and in the middle of the scrubbed region (lower curve); (d)-(f) $\mathrm{Cu}_{2} \mathrm{p}_{3 / 2}$, C1s, and O1s core level spectra measured on the as-received sample; (g)-(i) $\mathrm{Cu} 2 \mathrm{p}_{3 / 2}, \mathrm{C} 1 \mathrm{~s}$, and $\mathrm{O} 1 \mathrm{~s}$ core level spectra measured in the periphery (violet) and in the center (red) of the scrubbed region.

likely that the $\mathrm{O}$ atoms desorb as $\mathrm{O}_{2}$ whereas the $\mathrm{C}$ atoms bind to each other and condense in graphitic-like organized network.

Therefore the thin $\mathrm{C}$ layer which forms on the $\mathrm{Cu}$ surface exposed to prolonged electron irradiation at $500 \mathrm{eV}$ is due to (i) the $\mathrm{C}-\mathrm{C}$ bonds rearrangement from the open-chain geometry, typical for aliphatic hydrocarbons, to the honeycomb arrangement characteristic of the graphitic materials, owing to the transition of the $\mathrm{C}$ atoms from the $\mathrm{sp}^{3}$ to $\mathrm{sp}^{2}$ hybridization state, and (ii) the deposition of a thin graphitic-like layer after the dissociation of C-containing gas phase molecules (likely 
$\mathrm{CO}$ and $\mathrm{CO}_{2}$ ) present in the residual pressure of the ultrahigh vacuum chamber.

In order to verify the occurrence of electron beaminduced $\mathrm{C}$ growth, the sample was $\mathrm{Ar}^{+}$sputtered to remove any surface contaminant and then the clean surface was irradiated in a fixed point by electrons at $500 \mathrm{eV}\left(10 \mu \mathrm{A}, Q=3.6 \times 10^{-2} \mathrm{C} / \mathrm{mm}^{2}\right)$. In principle, the clean $\mathrm{Cu}$ surface should not suffer any chemical modification by electron irradiation. The SEY curve measured on the $\mathrm{Ar}^{+}$sputtered surface before and after the electron scrubbing are compared in Fig. 3(a). The $\delta_{\max }$ value of 1.4 measured on the clean $\mathrm{Cu}$ surface decreases down to 1.2 in the area exposed to the electron beam. Accordingly, the $\mathrm{C} 1 \mathrm{~s}$ spectrum, which is nearly flat for the clean surface, shows an intense peak at $284.3 \mathrm{eV}$ [Fig. 3(c)], indicative of a graphitic C layer, which screens the $\mathrm{Cu} 2 \mathrm{p}_{3 / 2}$ substrate signal appearing less intense than on the clean surface [Fig. 3(b)]. On the contrary, the amount of surface oxygen remains negligible [Fig. 3(d)]. Thus, the electron beam dissociates the adsorbed molecules promoting the formation of $\mathrm{sp}^{2} \mathrm{C}-\mathrm{C}$ bonds while desorbing $\mathrm{O}$ atoms possibly contained in the contaminants. In the $\mathrm{e}^{-}$irradiated area, i.e., in correspondence of the $\mathrm{C}$ spot, the $\delta_{\max }$ value coincides with that of the region scrubbed at $500 \mathrm{eV}$ in the as-received sample [see Fig. 2(a)], confirming the mitigating effect of a thin graphitic-like layer on the secondary electron emission of metallic surfaces.
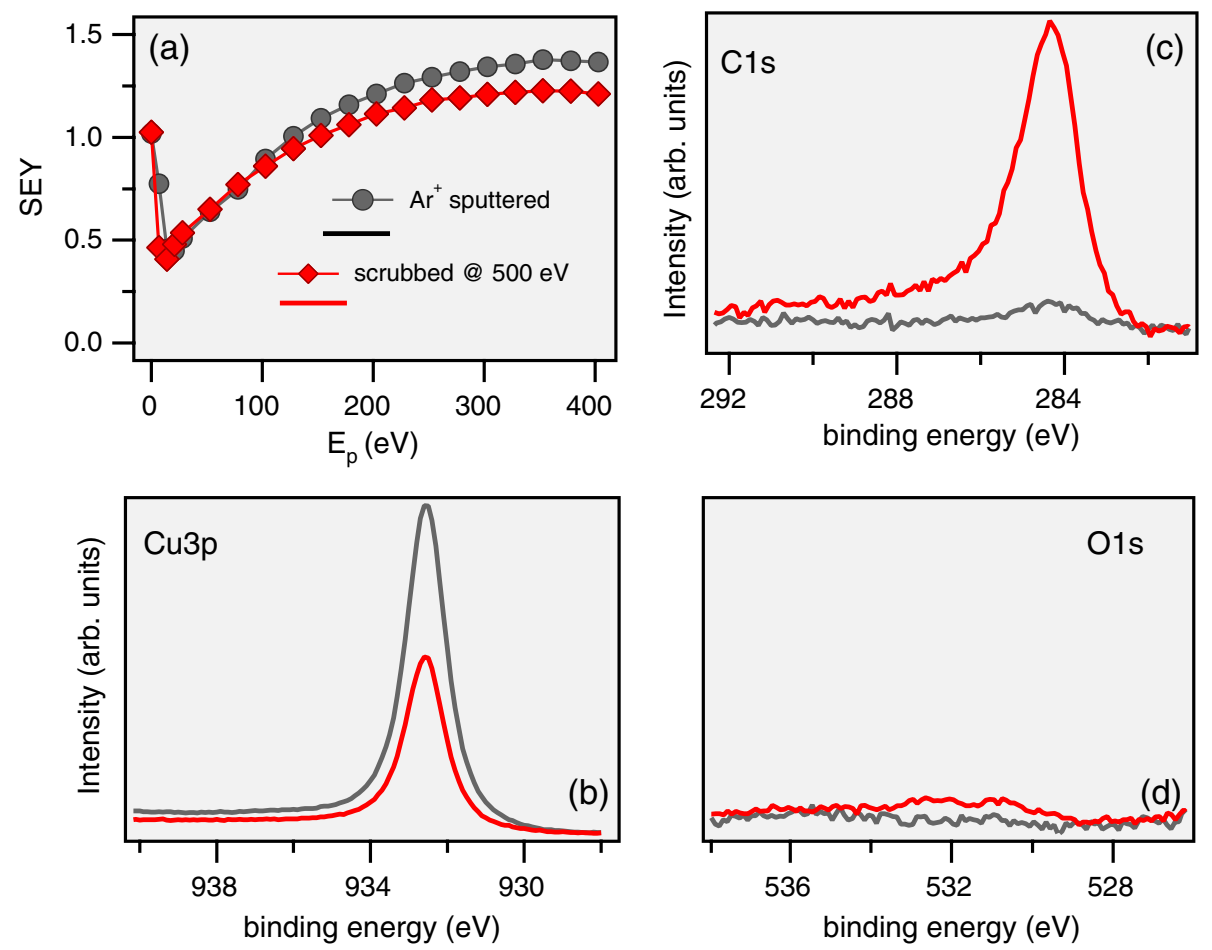

FIG. 3. (a) SEY curves measured on the colaminated Cu sample for LHC beam screen cleaned by $\mathrm{Ar}^{+}$sputtering (grey circles) and after the subsequent scrubbing with $500 \mathrm{eV}$ electrons $\left(10 \mu \mathrm{A}, Q=3.6 \times 10^{-2} \mathrm{C} / \mathrm{mm}^{2}\right)$ (red diamonds); (b) $-(\mathrm{d}) \mathrm{Cu} 2 \mathrm{p}_{3 / 2}$, $\mathrm{C} 1 \mathrm{~s}$, and $\mathrm{O} 1 \mathrm{~s}$ core level spectra measured on the $\mathrm{Ar}^{+}$sputtered (grey lines) and on the scrubbed surface (red lines). 
after such additional scrubbing exhibits the asymmetric profile peaked at $284.3 \mathrm{eV}$ typical of $s p^{2} \mathrm{C}$ atoms [Fig. 4(b)]. In this particular case the growth of additional $\mathrm{C}$ under the action of the beam is marginal as shown by the comparable $\mathrm{C} 1 \mathrm{~s}$ intensities measured before and after the scrubbing at $500 \mathrm{eV}$. In agreement with the behavior observed before, the SEY curve measured on the graphitized surface shows a $\delta_{\max }$ value of 1.2 [Fig. 4(a)], confirming the beneficial effect of ultrathin graphitic-like $\mathrm{C}$ films on the secondary emission properties of copper technical surfaces.

By combining the results obtained at $E_{p}$ of 500 and $10 \mathrm{eV}$ it is possible to describe the electron scrubbing of technical $\mathrm{Cu}$ surfaces as occurring in two steps, where the first step consists in the electron-induced desorption of
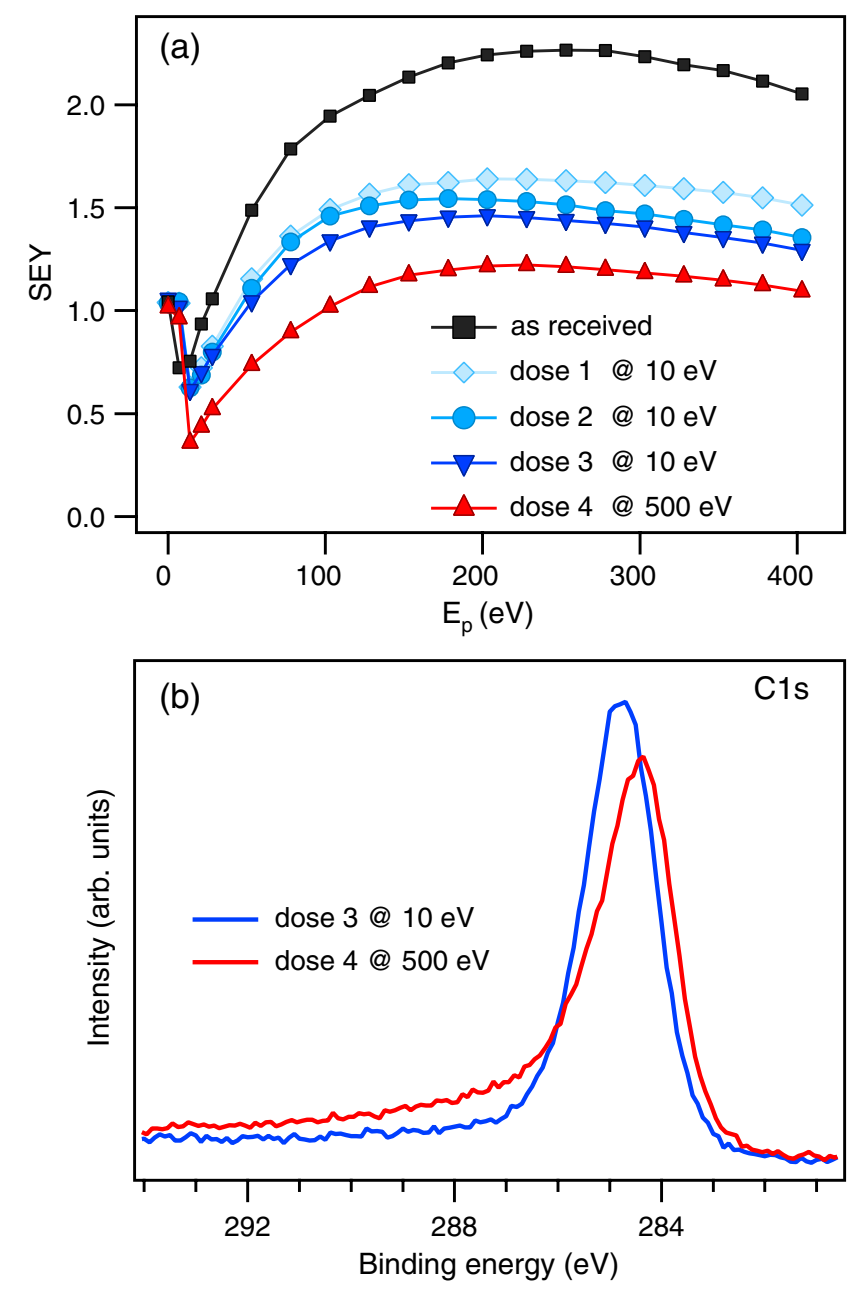

FIG. 4. (a) SEY curve measured on the colaminated $\mathrm{Cu}$ sample for LHC beam screen as-received and in the middle of the area $\left(3 \times 3 \mathrm{~mm}^{2}\right)$ scrubbed with $10 \mathrm{eV}$ electrons (dose $1: Q=3.2 \times$ $10^{-3} \mathrm{C} / \mathrm{mm}^{2}$; dose $2: Q=4.8 \times 10^{-3} \mathrm{C} / \mathrm{mm}^{2}$; dose $3: Q=$ $1.1 \times 10^{-2} \mathrm{C} / \mathrm{mm}^{2}$ ), and afterwards scrubbed with $500 \mathrm{eV}$ electrons (dose 4: $Q=1.2 \times 10^{-3} \mathrm{C} / \mathrm{mm}^{2}$ ); (b) $\mathrm{C} 1$ s core level spectra taken on the sample surface scrubbed at $10 \mathrm{eV}$ (dose 3) and subsequently scrubbed at $500 \mathrm{eV}$ (dose 4). weakly bound contaminants that occurs indifferently at 10 and at $500 \mathrm{eV}$ and corresponds to a partial decrease of $\delta_{\max }$, and the second step, activated by more energetic electrons and becoming evident at high doses, which increases the number of graphitic-like $\mathrm{C}-\mathrm{C}$ bonds via the dissociation of adsorbates already contaminating the asreceived surface or accumulating on this surface during irradiation.

\section{CONCLUSIONS}

We have shown that the SEY of colaminated $\mathrm{Cu}$ samples for LHC beam screens can be decreased by electron scrubbing. However, lowering the initial $\delta_{\max }$ of 2.1 to values below 1.4 requires the formation of a graphitic-like film. This occurs via electron beam-induced reactions in the C-containing contaminating layer covering the as-received sample, and/or via electron beam-induced dissociation of adsorbates coming from the residual gas of the vacuum chamber or released by the $\mathrm{e}^{-}$gun filament (typically $\mathrm{CO}$ and $\mathrm{CO}_{2}$ ), whose fragments partly desorb and partly organize in graphitic domains. We also report here the evidence that the $\mathrm{e}^{-}$beam-induced $\mathrm{C}$ growth can occur on clean $\mathrm{Cu}$ surfaces that would be in principle stable to electron irradiation. Because of this evidence some concern arises with respect to the comparison of data taken at different base pressures and by using differently degassed electron beam filaments. Undoubtedly more systematic studies are required to fully understand the processes leading to surface conditioning. We confirm the mitigating effect of thin graphitic-like films on the surface SEY, and demonstrate the limited scrubbing effectiveness of low kinetic energy electrons. As a matter of fact, neither the low kinetic energy impinging electrons $\left(E_{p}=10 \mathrm{eV}\right)$ nor the low energy secondary electrons coming from the bulk of the sample are efficient towards surface graphitization, but the interaction with energetic electrons seems to be indispensable to convert the adsorbed $\mathrm{C}$ atoms into a graphitic-like network. These results, having a direct relevance for LHC, might also widen the general perspective of accelerator wall conditioning and may be of interest to the much wider community studying the SEY surface properties in various fields of research.

\section{ACKNOWLEDGMENTS}

This work has been supported by INFN- NTA and Group $\mathrm{V}$. The assistance of the technical team of DAFNE-L is deeply acknowledged.

[1] S. T. Lai, Fundamentals of Spacecraft Charging: Spacecraft Interactions with Space Plasmas (Princeton University Press, Princeton, NJ, 2011).

[2] Proceedings of the 6th International Workshop on Multipactor, Corona and Passive Intermodulation in 
Space RF Hardware (MULCOPIM '08), Valencia, Spain, and references therein.

[3] J. Chen, E. Louis, J. Verhoeven, R. Harmsen, C. J. Lee, M. Lubomska, M. van Kampen, W. van Schaik, and F. Bijkerk, Appl. Surf. Sci. 257, 354 (2010).

[4] H. Seiler, J. Appl. Phys. 54, R1 (1983).

[5] R. Cimino, I. R. Collins, M. A. Furman, M. Pivi, F. Ruggiero, G. Rumolo, and F. Zimmermann, Phys. Rev. Lett. 93, 014801 (2004).

[6] R. Cimino, Nucl. Instrum. Methods Phys. Res., Sect. A 561, 272 (2006).

[7] R. Cimino, I. R. Collins, and V. Baglin, Phys. Rev. ST Accel. Beams 2, 063201 (1999).

[8] F. Zimmermann, CERN, LHC Project Report No. 95, 1997.

[9] G. Rumolo and F. Zimmermann, CERN Report No. SLNote-2002-016, 2002.

[10] Technical Report No. CERN-SL-Note-2002-016; see also The ECLOUD Program [http://wwwslap.cern.ch/ collective/electron-cloud/Programs/Ecloud/ecloud.html].

[11] M. A. Furman and M. Pivi, Phys. Rev. ST Accel. Beams 5, 124404 (2002).

[12] G. Iadarola, PyECLOUD, in Electron Cloud Simulations, Meeting, 2011.

[13] CERN Report No. CERN-2002, edited by G. Rumolo and F. Zimmermann, 2002.

[14] The 31st ICFA Advanced Beam Dynamics Workshop on Electron-Cloud Effects ECLOUD'04, Napa, California, 2004, edited by M. Furman [http://icfa-ecloud04.web .cern.ch/icfa-ecloud04/], and references therein.

[15] Proceedings of the International Workshop on ElectronCloud Effects (ECLOUD'07), Daegu, Korea, 2007 (High Energy Accelerator Research Organization, KEK, Tsukuba, Ibaraki, Japan, 2007) [http://airex.tksc.jaxa.jp/ $\mathrm{pl} / \mathrm{dr} / \mathrm{AA} 0063628000 / \mathrm{en}]$, and references therein.

[16] Proceedings of the International Workshop on Multibunch Instabilities in Future Electron and Positron Accelerators (MBI'97), edited by Y.H. Chin (KEK, Tsukuba, 1997).

[17] Proceedings of the International Workshop on Two-Stream Instabilities in Particle Accelerators and Storage Rings (KEK, Tsukuba, Japan, 2001) [http://conference.kek.jp/ two-stream/].
[18] F. Zimmermann, CERN Report No. CERN-SL-2001-003 DI, 2001.

[19] M. Nishiwaki and S. Kato, Vacuum 84, 743 (2009).

[20] R. Cimino, M. Commisso, D. R. Grosso, T. Demma, V. Baglin, R. Flammini, and R. Larciprete, Phys. Rev. Lett. 109, 064801 (2012).

[21] C. YinVallgren, G. Arduini, J. Bauche, S. Calatroni, P. Chiggiato, K. Cornelis, P. C. Pinto, B. Henrist, E. Métral, H. Neupert, G. Rumolo, E. Shaposhnikova, and M. Taborelli, Phys. Rev. ST Accel. Beams 14, 071001 (2011).

[22] M. Nishiwaki and S. Kato, J. Vac. Sci. Technol. A 25, 675 (2007).

[23] L. Calliari, M. Filippi, and N. Laidani, Surf. Interface Anal. 36, 1126 (2004).

[24] R. Banhart, Rep. Prog. Phys. 62, 1181 (1999).

[25] C. R. Arumainayagam, H.-L. Lee, R. B. Nelson, D. R. Haines, and R.P. Gunawardane, Surf. Sci. Rep. 65, 1 (2010).

[26] D. Syomin and B. E. Koel, Surf. Sci. 492, L693 (2001).

[27] O. Guise, H. Marbach, J. Levy, J. Ahner, and J. Y. Jr., Surf. Sci. 571, 128 (2004).

[28] C. Scheuerlein and M. Taborelli, J. Vac. Sci. Technol. A 20, 93 (2002).

[29] P. Roediger, H. D. Wanzenboeck, G. Hochleitner, and E. Bertagnolli, J. Vac. Sci. Technol. B 27, 2711 (2009).

[30] B. Yakshinskiy, R. Wasielewski, E. Loginova, M. Hedhili, and T. E. Madey, Surf. Sci. 602, 3220 (2008).

[31] C. Chauvet, F. Polack, M. G. Silly, B. Lagarde, M. Thomasset, S. Kubsky, J.P. Duval, P. Risterucci, B. Pilette, I. Yao, N. Bergeard, and F. Sirotti, J. Synchrotron Radiat. 18, 761 (2011).

[32] J. Ghijsen, L. H. Tjeng, J. van Elp, H. Eskes, J. Westerink, G. A. Sawatzky, and M. T. Czyzyk, Phys. Rev. B 38, 11322 (1988).

[33] J. Díaz, G. Paolicelli, S. Ferrer, and F. Comin, Phys. Rev. B 54, 8064 (1996).

[34] R. Haerle, E. Riedo, A. Pasquarello, and A. Baldereschi, Phys. Rev. B 65, 045101 (2001).

[35] R. Larciprete, P. Lacovig, S. Gardonio, A. Baraldi, and S. Lizzit, J. Phys. Chem. C 116, 9900 (2012).

[36] A. Leontowicz and A. Hitchcock, J. Vac. Sci. Technol. B 30, 030601 (2012). 